\title{
18
}

\section{FORGIVENESS: INTEGRAL TO A SCIENCE OF CLOSE RELATIONSHIPS?}

\author{
FRANK D. FINCHAM
}

If we really want to love, we must learn how to forgive.

-Mother Teresa

It is easier to forgive an enemy than to forgive a friend.

-William Blake

Paradoxically, fulfillment of our deepest needs occurs in intimate relationships, in which we are also likely to experience emotional injuries. For if there is one certainty in life, it is that romantic partners are not perfect, despite our tendency to idealize them (e.g., Murray, Holmes, \& Griffin, 1996); it is a rare person who has never felt "wronged," "let down," "betrayed," or "hurt" by a relationship partner. In close relationships, we voluntarily make ourselves most vulnerable to another human being by linking the realization of our needs, aspirations, and hopes to the goodwill of our relationship partner (for related ideas, see chap. 17, this volume). Rendering ourselves vulnerable makes possible the profound sense of well-being that can be experienced in close relationships. But at the same time, the imperfection of any partner means that hurt or injury is virtually inevitable, and when it occurs, the hurt is particularly poignant precisely because we have made ourselves vulnerable.

In the face of such injury, negative feelings (e.g., anger, resentment, disappointment) are common. Motivation to avoid the source of the harm,

The author is grateful to Steven Beach and Steven Graham for their helpful comments on an earlier draft of this chapter. 
or even a desire to retaliate or seek revenge, is also typical. Indeed, some have argued that retaliation in such circumstances "is deeply ingrained in the biological, psychological, and cultural levels of human nature" (McCullough \& vanOyen Witvliet, 2002, p. 446), a position consistent with Aristotle's (trans. 1939) view of anger as "a longing, accompanied by pain, for a real or apparent revenge for a real or apparent slight" (p. 173). This creates a particular challenge because hurts inflicted by an intimate partner have the potential to corrode, disrupt, and even end the relationship.

Understanding how partners respond to such hurt is critical to understanding intimate relationships. One means of dealing with such hurt is through forgiveness, which is likely the basis for Mother Teresa's statement cited at the beginning of this chapter. At the same time, the fact that the hurt occurs in a context in which we have intentionally made ourselves vulnerable is probably why William Blake asserted that forgiving an intimate other may be more difficult than forgiving an enemy.

\section{EMERGENCE OF RESEARCH ON FORGIVENESS IN CLOSE RELATIONSHIPS}

In light of the observations just offered, it is perhaps surprising that the study of forgiveness is a relative latecomer to the literature on close relationships. The first published data that specifically focused on forgiveness in intimate relationships appear to have emerged only in 2000. In this regard, research on close relationships has followed the lead of the broader scientific literature. Before 1985 only five studies on forgiveness had been published (Worthington, 1998). By 1998, McCullough, Exline, and Baumeister were able to provide an annotated bibliography on forgiveness that contained 46 studies. It is perhaps not surprising that these authors noted that "scientific understanding of the concept of forgiveness is quite limited" (p. 194). The relative lack of research on forgiveness likely reflects this construct's association with religion. This association did not engender hostility or disdain toward forgiveness in the social sciences, but it may have caused it to seem insufficiently relevant, important, or amenable to scientific study (McCullough et al., 1998).

The astute reader may note, however, that relationship researchers have long recognized that the less than ideal behavior of intimates toward each other poses a challenge for relationships, suggesting that we may have been researching forgiveness all along but just calling it something else. This observation demands attention and is therefore briefly addressed.

The closest construct to forgiveness in intimate relationship research is accommodation or the willingness to respond to potentially destructive partner behavior by inhibiting "tendencies to react destructively" and instead to "engage in constructive reactions" (Rusbult, Verette, Whitney, Slovik, \& 
Lipkus, 1991, p. 53; see also chap. 17, this volume). However, potentially destructive partner behavior may take many forms, and only when this behavior represents a perceived "wrong" is forgiveness relevant. In addition, accommodation might occur because potentially destructive partner behavior is construed in such a way that its destructive nature is ignored, overlooked, or downplayed, or when fully recognized, is condoned or excused. Under these circumstances, forgiveness is not a relevant concern. Thus, although accommodation and forgiveness overlap under certain conditions, accommodation is a much broader construct than forgiveness. Accommodation therefore cannot be equated with forgiveness.

Given this historical context, why has psychological research on forgiveness flourished recently, with 52 peer reviewed articles containing "forgive" or "forgiveness" in their title appearing in 2007 alone (PsycINFO). In the late 1980s the zeitgeist in psychology began to change to accommodate the study of human strengths and virtues. This shift ultimately culminated in the formal naming of a field of positive psychology in 1998 by the then APA president, Martin Seligman. The emergence of positive psychology contributed to a propitious environment for the growth of forgiveness research. Just as important, in 1998 the Templeton Foundation made available $\$ 10$ million for research on forgiveness. Given these developments, the explosion of forgiveness research in the past decade was inevitable.

Finally, it is noteworthy that the emergence of positive psychology occurred almost simultaneously with the coming of age or what Berscheid (1999) called the greening of relationship science. Although a consensus definition is yet to emerge, the study of forgiveness in close relationships has proceeded in isolation from the broader positive psychology literature, but in this regard it appears to be no different from its parent literature on close relationships.

\section{WHAT IS FORGIVENESS AND HOW IS IT STUDIED?}

How researchers conceptualize a construct shapes how it is measured and used in subsequent research. It therefore behooves us to clarify exactly what is meant by forgiveness.

\section{Conceptualizing Forgiveness}

Because it is a complex construct, considerable effort has been expended on conceptualizing forgiveness and discerning how it might best be studied. Although a consensus has yet to emerge, central to various approaches to forgiveness is the idea of a freely chosen motivational transformation in which the desire to seek revenge and to avoid contact with the transgressor is overcome. This position is consistent with many philosophical writings that define forgiveness as the forswearing of resentment toward the wrongdoer. No- 
tice the idea of effort by the forgiver embodied in this view (for an alternative view of forgiveness as a nonconscious process, see chap. 15, this volume). To forgive entails a struggle to overcome the negative feelings that result from being wrongfully harmed, and the magnitude of this struggle differs across individuals. This view immediately distinguishes forgiveness from related constructs such as forgetting (i.e., passive removal of the offense from consciousness; to forgive is more than not thinking about the offense), condoning (i.e., no longer viewing the act as a wrong and removing the need for forgiveness), and pardon (granted only by a representative of society such as a judge). Thus, the common phrase "forgive and forget" is misleading because forgiveness is possible only in the face of a remembered wrong.

It is this latter observation that helps undermine Nietzsche's (1887) argument that forgiveness is a sign of weakness. As noted, forgiveness requires the victim to acknowledge adverse treatment that entitles him or her to justifiably feel negatively toward the transgressor; it thus requires the strength to assert a right, the right to better treatment than that shown by the transgressor. Absent such assertion, conciliatory actions can reflect factors such as condoning of the transgressor's behavior, a strategic ploy, a desire to appease the transgressor, and so on. Accordingly, it is incorrect to label such behaviors forgiveness. In addition to asserting one's claim to a position of moral authority vis-à-vis the transgressor, forgiveness requires the strength to relinquish this position of moral authority and release the transgressor from the debt incurred by the transgression. As anyone who has attempted to forgive knows, forgiving is not easy; in fact, it may prove extraordinarily difficult because it involves working through, not avoiding, emotional pain. It is little surprise then that Mahatma Ghandi (2000) asserted that "the weak can never forgive. Forgiveness is the attribute of the strong" ( $p$. $301)$.

It may be argued that forgiving subverts the course of justice and that when forgiveness occurs justice is not served. In the aftermath of a transgression, it is common for victims to experience a "moral injury" in the sense that their beliefs about what is right and wrong have been assailed. This experience may lead to a strong desire to set the scale of justice back in balance. Forgiveness does not preclude doing so, and the pursuit of justice (e.g., appropriate punishment, compensation) can be justified on numerous grounds, such as a necessary corrective to shape future behavior, to protect others from danger, and so on. There is thus no contradiction between forgiving a transgressor and pursuing justice (for further discussion, see Exline, Worthington, Hill, \& McCullough, 2003).

Finally, in the relationship context, forgiveness needs to be distinguished from reconciliation. Although an inherently interpersonal construct, forgiveness occurs primarily within the individual. It is known to be influenced by interpersonal events, such as expressions of remorse by the wrongdoer, but the motivational change involved occurs largely at the intraindividual level. 
Reconciliation, in contrast, restores a relationship between persons and is a dyadic process that requires appropriate participation by both parties: It involves the restoration of violated trust and requires the goodwill of both partners. Forgiveness increases the likelihood of reconciliation but is not synonymous with it. There is no contradiction involved in forgiving a wrongdoer and also ending one's relationship with the person. Likewise, reconciliation can occur without forgiveness, further emphasizing the need to distinguish between the two actions.

\section{Operationalizing Forgiveness}

Most research on forgiveness has focused on forgiveness either as a response to a specific transgression or as a personality trait (forgivingness). In both cases it has been operationalized as the reduction of negative motivational tendencies toward the transgressor. Perhaps the most widely used offense-specific measure is McCullough, Rachal, et al.'s (1998) and McCullough, Worthington, and Rachel's (1997) Transgression-Related Interpersonal Motivation (TRIM) Inventory. The TRIM comprises 12 items that assess the motivation to seek revenge and to avoid the offender. Although McCullough and colleagues assumed that revenge motives and avoidant motives are distinct dimensions, others assumed that they are indistinguishable in the close relationship context (e.g., Worthington $\&$ Wade, 1999). In such relationships, the desire to even the score and the desire to maintain a significant physical and psychological distance from the offending partner can often coexist.

In a similar vein, the most widely used measure to assess the disposition to forgive others is the Dissipation-Rumination Scale, which Caprara (1986) developed to study aggression. The 15 Likert-type items are positively related to retaliation after a transgression. A more recent measure specifically developed to assess dispositional forgiveness, the Transgression Narrative Test of Forgivingness (Berry, Worthington, Parrott, O'Connor, \& Wade, 2001), reflects sophisticated use of item-response scaling and is one of the very few measures to use spouse reports to validate responses (self and partner ratings correlated .60). It asks a single question about forgiveness after each of five scenarios. The scale thus relies on a respondent's understanding of the construct of forgiveness.

It is interesting that laypersons tend to view positive features as more representative of forgiveness than a decrease in negativity (Kearns $\&$ Fincham, 2005). In this regard, they appear to be closer to the view of philosophers who have noted that forgiveness is "an attitude of real goodwill towards the offender as a person" (Holmgren, 1993, p. 34) or "the attitude of respect which should always characterize interpersonal behavior" (Downie, 1971, p. 149). There is a lack of agreement among researchers on whether forgiveness requires a benevolent or positive response (e.g., compassion, empathy) to 
the offender or whether the absence of negative responses (e.g., resentment, anger, avoidance) is sufficient (Exline et al., 2003; Fincham, 2000). Indeed, forgiveness may be unidimensional in noncontinuing relationships but have both positive and negative elements in continuing close relationships (Worthington, 2005).

Because the positivity view of forgiveness cannot be inferred from the absence of unforgiveness, it is worth noting that both dimensions have been built into two measures specifically designed to assess forgiveness in close relationships. The nine-item Relationship Forgiveness Scale-Event (Fincham, Beach, \& Davila, 2004) assesses retaliation (e.g., "I did something to even the score"), withdrawal (e.g., "I didn't want to have anything to do with her/him"), and benevolence (e.g., "It was easy to feel warmly again toward my partner"). The Relationship Forgiveness Scale-Disposition (Fincham \& Beach, 2002) assesses the general tendency to forgive the partner while tapping both retaliation and benevolence. As will soon be evident, positive and negative dimensions of forgiveness have different correlates. Before turning to findings on forgiveness in relationships, we note that the TRIM has been expanded to include a positive dimension. An initial longitudinal study showed that in the first few weeks following a transgression, avoidance and revenge motivation decreased, whereas benevolence motivation did not change (McCullough, Fincham, \& Tsang, 2003).

\section{WHAT HAVE WE LEARNED ABOUT FORGIVENESS IN CLOSE RELATIONSHIPS?}

A thorough review of what has been learned about forgiveness in close relationships is beyond the scope of this chapter, so what follows is only a brief overview of major findings (see Fincham, Hall, \& Beach, 2005). Studies have shown that forgiveness is robustly and positively related to core relationship constructs. But in the absence of an integrative theory of forgiveness in close relationships, available research tends to be somewhat fragmented. Given the centrality of relationship satisfaction in relationship research, it is not surprising that substantial attention has been given to the association between relationship satisfaction and forgiveness.

\section{Relationship Satisfaction}

Several studies have documented a positive association between relationship satisfaction and forgiveness (e.g., Fincham, 2000; Paleari, Regalia, $\&$ Fincham, 2005). It appears that the association between forgiveness and relationship quality is bidirectional. There is emerging evidence that marital quality predicts later forgiveness (Fincham \& Beach, 2007; Paleari et al., 2005), as well as data showing that forgiveness predicts later marital satisfac- 
tion (e.g., Fincham \& Beach, 2007). Among newlyweds, McNulty (2008) found a more complex longitudinal relationship in that more forgiveness led to a smaller decline in satisfaction over time and less forgiveness led to a greater reduction in satisfaction, but only for spouses married to partners who infrequently engaged in negative behavior. Among spouses married to partners who frequently engaged in negative behavior, increased forgiveness appeared to be harmful over time for marital satisfaction, whereas decreased forgiveness appeared to be beneficial.

Relationship satisfaction also appears to influence documented differences between victim and perpetrator perspectives on transgressions, which may explain why forgiveness and satisfaction are related. Specifically, victims tend to overlook details that facilitate forgiving and embellish their memories with details that make forgiving more difficult, whereas transgressors tend to embellish details, such as extenuating circumstances, that facilitate forgiving (Stillwell \& Baumeister, 1997). However, individuals in highly satisfying relationships are less likely to exhibit these self-serving biases than individuals in less satisfying relationships (Kearns \& Fincham, 2005). Existing data are consistent with a causal sequence in which relationship quality leads to more benign interpretations of a transgression, which in turn promote forgiveness. Relationship satisfaction may therefore help to meet the challenge forgiveness poses whereby the victimized partner has to cancel a debt that is often perceived as bigger than the debt acknowledged by the transgressing partner.

Although the association between satisfaction and forgiveness is robust, the mechanism underlying this link remains unclear. McCullough, Rachal, et al. (1998) proposed several possible mechanisms, including a greater likelihood of confession and apology in satisfied intimate relationships, leading to more forgiveness. Another possibility is that commitment facilitates forgiveness.

\section{Commitment}

Because both commitment and forgiveness are believed to promote prorelationship motives, it is perhaps not surprising that the two constructs are positively related (e.g., McCullough, Rachal, et al., 1998; see also chap. 17 , this volume). As suggested, the forgiveness-commitment association could be driven by commitment, as highly committed individuals may be more motivated to forgive simply because they intend to remain in their current relationship. In fact, some experimental data show that greater commitment facilitates forgiveness (chap. 17, this volume). On the other hand, it is also plausible that following a relational transgression, forgiveness has to occur for damaged closeness and commitment to be restored: It is difficult for the hurt individual to feel close to his or her offending partner if he or she still harbors a grudge about the transgression. Consistent with this viewpoint, 
Tsang, McCullough, and Fincham (2006) offered longitudinal evidence that forgiveness promotes increases in commitment, although they also found limited evidence that effects also ran in the opposite direction. Finally, there is evidence that attributions may mediate the association between commitment and forgiveness, as committed individuals tend to interpret their partners' betrayals in a more benevolent manner, which may thereby promote forgiveness.

\section{Attributions}

As in the broader forgiveness literature, attributions or explanations for the offending behavior predict forgiveness among intimates (e.g., Friesen, Fletcher, \& Overall, 2005). Fincham, Paleari, and Regalia (2002) found that benign attributions predicted forgiveness both directly and indirectly through lessening negative emotional reactions to the transgression and increasing empathy toward the transgressing spouse. Similarly, adolescents' attributions for negative parent behavior were directly related to forgiving and indirectly related through affective reactions to the behavior (Paleari et al., 2003). It is interesting that attributions moderate the well-established impact of transgression severity on forgiveness. Among dating partners, perceived transgression severity was strongly related to forgiveness only when conflictpromoting attributions (e.g., inferring greater intent, selfish motivation, blameworthiness) were made for partner behavior. When benign attributions were made, severity was not significantly related to forgiveness (Fincham, Jackson, \& Beach, 2005). Finally, forgiveness mediates the association between attributions and behavior toward one's spouse (Fincham, 2000) or romantic partner (Eaton \& Struthers, 2006), whereas adolescent forgiving is associated with a decreased likelihood of subsequent parent-adolescent conflict (Paleari et al., 2003).

\section{Conflict}

In addition to the link between forgiveness and conflict noted previously, unresolved conflict provides a potential mechanism that links forgiveness and relationship satisfaction. Specifically, it can be argued that transgressions that are not forgiven may spill over into future conflicts and, in turn, impede their resolution, thereby putting the couple at risk of developing the negative cycle of interaction that characterizes distressed relationships. Supporting this line of reasoning, retaliation and avoidance among husbands and a lack of benevolence among wives were linked to ineffective conflict resolution (Fincham et al., 2004). Moreover, for wives the positive dimension of forgiveness or benevolence predicted husbands' reports of better conflict resolution 12 months later, controlling for initial levels of conflict resolution and degree of hurt (Fincham, Beach, \& Davila, 2007). 


\section{Empathy}

Empathy is a relationship construct that appears to play an important role in the forgiveness process (e.g., McCullough, Rachal et al., 1998), and its connection to forgiveness was mentioned earlier. There is some evidence that empathy is a better predictor of forgiveness for husbands than wives, potentially because empathic behavior tends to be less common for men in relationships and therefore more influential (Fincham et al., 2002). The importance of empathy is further emphasized by the substantial body of research on promoting forgiveness in relationships in which attempts to increase empathy play a central role.

\section{Applied Research on Inducing Forgiveness}

Several interventions, typically delivered in the context of psychoeducational groups or relationship-enrichment programs, have been shown to increase forgiveness in romantic relationships. Although an initial analysis of 14 studies documented a linear relationship between intervention length and its efficacy (Worthington, Sandage, \& Berry, 2000), a more recent meta-analysis of 27 studies showed that although amount of time spent in the intervention predicted efficacy, intervention status (full vs. partial vs. no intervention) predicted outcome over and beyond intervention duration (Wade, Worthington, \& Meyer, 2005). Most of the interventions included helping couples understand what forgiveness is and is not (87\%), encouraging them to recall the hurt (95\%), and helping victims empathize with the offending partner $(89 \%)$. Of these components, amount of time spent on empathy was reliably related to intervention effect size.

In a field in which it is difficult to do experimental research, intervention studies have the potential to provide much needed information on mechanisms involved in forgiveness. To date, however, this potential remains largely untapped because the dismantling of these multicomponent interventions to determine the active ingredients for changing forgiveness is notably absent. Also absent are data on the impact of induced forgiveness on relationship outcomes. Thus, the potential of applied research to advance understanding of forgiveness remains unrealized.

\section{TOWARD A MORE COMPLETE UNDERSTANDING OF FORGIVENESS AMONG INTIMATES}

Although the need for an integrative theory of forgiveness in close relationships should by now be quite obvious, space limitations preclude its realization in the present context. The remainder of the chapter is therefore 
devoted to identifying some critical issues overlooked in relationship forgiveness research that are critical to advancing such a theory.

\section{Relationships Have a History: Specific Hurts and Hurtful Relationships}

The imperfection of relationship partners necessarily gives rise to a history of hurts in any relationship. This means that forgiveness may not pertain to a particular transgression even when it appears to do so. Rather, the specific transgression in question may (knowingly or unknowingly) represent the accumulated hurts of numerous, functionally equivalent prior acts. The task of forgiveness is potentially rendered more difficult because it may now pertain to forgiving multiple harm-doing events, a possibility that has been ignored in research. The importance of this oversight is easily illustrated.

Consider a couple in which one partner has been unfaithful. The aggrieved partner is unlikely to respond similarly to the transgression without regard to whether this is the first instance or the tenth time the partner has been unfaithful. In the latter case, the aggrieved partner may be experiencing ongoing hurt from the prior transgressions, making this transgression fundamentally different than it would be for a partner experiencing it for the first time. In short, the history of infidelity may transform the "wrong" that needs to be forgiven into one that involves not a hurtful event, or even a series of events, but a "hurtful relationship." A hurtful relationship carries with it a variety of broader concerns than does a single event, and it may arise in a variety of ways.

For instance, an aggrieved spouse may frequently be reminded of the harm resulting from a specific act (e.g., an adulterous one-night stand) by the partner's behavior (e.g., his or her comment on the appearance of an opposite-sex friend or stranger) because it can be viewed symbolically. In this event, the pain is likely to be experienced afresh and may be viewed as a new hurt, ultimately leading the spouse to conclude that he or she is in a hurtful relationship. The transition from a perceived hurtful event to a hurtful relationship is likely to be influenced by the extent to which a broad range of behaviors can be interpreted as symbolic of a prior transgression, by the spouse's proclivity to interpret the partner's behavior as symbolic of the transgression, and by the partner's attempts to avoid behaving in ways that lend themselves to such interpretation.

At a minimum, it will be important in future research to determine whether the identified transgression has occurred previously in the relationship and if so, to ascertain how it was dealt with. For example, if it included an apology by the transgressor and a statement that it would not happen again, the event would be viewed differently than if these accommodations had not occurred. Similarly, given a prior attempt(s) to ensure that the transgressing partner is aware of the previously inflicted injury, or the extent of 
the injury, forgiving the harm can be hypothesized to be less likely than in the absence of such attempts. In both the case of a prior apology and the victim's attempt to raise the transgressor's awareness, the occurrence of a subsequent similar transgression is likely to increase the probability that the injured spouse will view the relationship as hurtful. Finally, a broader perspective on the history of hurt reminds us that a hurtful partner's behavior may be experienced quite differently when it is functionally or symbolically similar to hurts experienced in other close relationships (e.g., at the hands of parents or a past partner). In such cases, it may be easier for the aggrieved partner to draw broader conclusions about the hurtful nature of the relationship.

\section{Relationships Include Implicit Processes: Explicit and Implicit Forgiveness}

The idea that forgiveness requires effort by the forgiver has important implications that need to be made explicit if they are to receive systematic research attention. First, it makes sense to talk about degrees of forgiveness when the referent is the accomplishment of forgiveness. Second, the accomplishment of forgiveness may or may not be achieved regardless of effort. Third, aggrieved partners likely use cues about their effort to make inferences about forgiveness, and those inferences may or may not be correct.

For example, it can be hypothesized that after exerting effort that leads to some positive interactions with the partner, a person may infer that he or she has forgiven the partner even though hurt feelings are not fully resolved. For this person, it is easy to imagine circumstances (e.g., a reminder of the transgression) that prompt negative thoughts related to forgiveness, making them relatively more accessible than positive thoughts. In contrast, for partners who have worked through the hurt and completely forgiven the partner, positive thoughts about forgiveness should be relatively more accessible regardless of situational cues. This accessibility effect should moderate the associations between forgiveness and related constructs.

To investigate such implicit forgiveness processes, Terzino, Fincham, and Cross (2008) had partners complete a priming task designed to bring to mind thoughts about a recent transgression. The partners then completed an 80 -item lexical decision task in which target stimuli comprised five positive (e.g., reconcile, understanding, compassion, acceptance, empathy) and five negative (e.g., retaliation, grudge, avoid, withdraw, revenge) forgiveness-related terms. The difference in mean reaction time between positive and negative forgiveness words was computed to identify completed forgivers (positive words < negative words) and uncompleted forgivers (positive words $>$ negative words). There was no mean difference between the two groups on self-reported forgiveness, commitment, closeness after the offense, or general closeness.

As hypothesized, implicit forgiveness moderated the relationship between forgiveness and commitment and closeness: The measures were highly 
correlated among completed forgivers ( $r$ from .45 to .61) and unrelated among uncompleted forgivers ( $r$ from .01 to .14). It therefore appears that a useful distinction can be made between explicit forgiveness and implicit forgiveness. Unlike explicit forgiveness, which can be accomplished relatively quickly, implicit forgiveness, like any automatic process, requires extensive practice to develop.

\section{Types of Forgiveness}

The finding just described concerning uncompleted forgiveness helps to illuminate why it is not uncommon to find a spouse who says and believes that he or she has forgiven the partner but who discovers that resentment or a desire for revenge is instigated during an interaction with the partner. When this happens with sufficient force or frequency, it is likely to result in a subjective experience of ambivalence and prompt reflection on the effort to forgive, which leads to the inference that forgiveness has not yet been fully accomplished. It is possible to characterize such ambivalent forgiveness in terms of the two forgiveness dimensions described earlier, because it appears to reflect high levels of both positives and negatives.

Accordingly, there may be heuristic value in identifying "types" of forgiveness defined by positive and negative forgiveness dimensions (see Figure 18.1). As just described, ambivalent forgiveness is characterized by an increase in positive behavior and affect toward the partner even though some negative motivation (e.g., a desire to teach him or her a lesson) continues. Completed forgiveness involves change on both forgiveness dimensions and is most likely to result in relationship repair. Probably important to complete forgiveness is the transition from the backward-looking victim role to a future orientation, one of the defining criteria of whether people adjust well following victimization (Holman \& Silver, 2005). Detached forgiveness occurs when a partner finds that he or she is less motivated to punish and avoid but not more motivated to engage with the partner. Because the lack of positive motivation may not have the same perceptual salience as the presence of negative motivations and negative interactions, detached forgiveness is a potential stopping point in the forgiveness process. However, the relative absence of positives might set the stage for deteriorating relationship satisfaction and result in a devitalized relationship characterized by indifference (Fincham \& Linfield, 1997).

Nonforgiveness occurs when, following a transgression, the victim is no less motivated to avoid or punish the partner and is not motivated to approach the partner. Such an individual is unlikely to characterize him- or herself as having "forgiven." However, in cases in which an individual had previously taken some initial behavioral steps toward forgiveness, any claim he or she makes about having forgiven may be either self-deceptive or promissory. In the former case, one might characterize the forgiveness as "hollow." 


\begin{tabular}{lllc}
\hline & \multicolumn{2}{c}{ Positive Dimension } \\
\hline Negative Dimension & High & $\begin{array}{c}\text { Ambivalent } \\
\text { forgiveness } \\
\text { Completed } \\
\text { forgiveness }\end{array}$ & Low \\
\hline
\end{tabular}

Figure 18.1. Forgiveness Typology Resulting From a Bidimensional Conception of Forgiveness. From Handbook of Forgiveness (p. 215), by E. L. Worthington, 2005, New York: Routledge. Copyright 2005 by Taylor \& Francis. Reprinted with permission.

Hollow forgiveness may be particularly difficult to resolve because the individual may assert that he or she has satisfied the requirements of forgiveness and may see little need to continue any process of forgiveness. Promissory forgiveness, on the other hand, might reflect an individual at a very early, but potentially productive, stage of the forgiveness process. It suggests an openness to continued change in motivation toward the partner, but this has the potential to create misunderstanding between partners, a topic considered in the next section.

It remains to be made explicit that the typology just outlined raises the question of whether there are natural points of discontinuity in the forgiveness process. Finding evidence of discontinuity sets the stage for identification of the "point of discontinuity" and for an intensive investigation of the transition between states. Taxometrics (Waller \& Meehl, 1998) provides a method to determine whether persons displaying forgiveness beyond a certain point behave in a qualitatively different manner from those displaying less forgiveness along a particular dimension. Although ignored thus far, the issue of types versus continua has the potential to change the future of forgiveness research.

\section{Relationships Involve Communication: Expressed Forgiveness and Private Forgiveness}

Initiating forgiveness and only later fully achieving it has the potential to set up interesting dynamics in an ongoing relationship, especially when the person verbally expresses forgiveness to the partner. There is the temptation to equate such statements with forgiveness even though they can be no more than a promissory note. Even when worded as such (though in the normal course of events one expects "I forgive you" to occur more commonly than "I want to try to forgive you"), the harm-doer is likely to experience the statement as performative and be puzzled, annoyed, or angry when incompletely resolved feelings of resentment about the harm-doing intrude upon subsequent discourse or behavior in the relationship. Thus, the words "I for- 
give you" can signal the beginning of a process yet be viewed as the end of the matter by the transgressor, who is likely to be only too willing to put the transgression in the past. The timing of such a verbalization, and where the speaker stands in regard to our typology of forgiveness, is likely to be particularly important. For example, the verbalization may have a different effect depending on whether the speaker is seen as ambivalent or detached.

Communication between partners about transgressions has been largely overlooked in forgiveness research (but see Kelley, 1998). Yet it is through such communication that the view of the victim communicated by the wrongdoing can be directly repudiated by the transgressor. Recognition of the bidirectional nature of communication also focuses attention on the victim's behavior. The extent of vacillation between positions in the space defined by the earlier described typology, and the duration of occupying a particular space, is likely to influence the victim's behavior. In short, how the victim responds to recurrent feelings of hurt-the subsequent inevitable hurts that result from a relationship with an imperfect partner, and so on--is likely to be important for understanding forgiveness.

Forgiveness-related communication is also important because genuinely motivated attempts to tell the partner that he or she is forgiven can easily be seen as, for instance, a putdown or a form of retaliation, and it might in itself end up being a source of hurt. And because the victim loses more than the transgressing partner gains from the transgression, such communication requires some skill to avoid it being seen as an overreaction and a possible source of conflict.

In short, there is a need to study both the process and the outcome of communication about transgressions, especially statements of forgiveness, and to distinguish these situations from one in which forgiveness occurs in the absence of any verbalized statements of forgiveness. The importance of such research is emphasized by the recent finding that positive attributions and relationship quality independently predicted higher private forgiveness, whereas only relationship quality predicted expressed forgiveness (Friesen et al., 2005).

\section{Relationships: An Antidote to the Same-Source Variance Problem}

As with the broader literature on forgiveness, most research on forgiveness in relationships is limited by the problem of same-source variance. This is because indices of forgiveness and its correlates are obtained from a single source, typically the victim. This obscures whether forgiveness reflects something about the forgiver or the partner's forgivability, or something about their relationship. When these effects were disaggregated, reactions to spouse transgressions were determined largely by relationship-specific factors rather than by individual tendencies toward forgivingness or the offending partner's forgivability (Hoyt, Fincham, McCullough, Maio, \& Davila, 2005). More- 
over, greater attention to the specific relationship in which forgiveness takes place suggests that it is intrinsically different across relationships (Maio, Thomas, Fincham, \& Carnelley, 2008).

The availability of analytic techniques such as the actor-partner interdependence model (Kenny, Kashy, \& Cook, 2006) has the potential to advance understanding of forgiveness in relationships. But even without the use of such techniques progress can be made by obtaining data from both partners. For example, showing that spouse-reported forgiveness predicts partner-reported outcomes is an improvement over most current data on forgiveness in relationships.

\section{The Dark Side of Forgiveness}

Forgiveness has been viewed in the relationship literature almost exclusively in a positive light. However, the finding that women in shelters (Burton, Gordon, \& Porter, 2004) and those who experience dating violence (Katz, Street, \& Arias, 1997) are more likely to return to their partner to the extent that they forgive him or her highlights the possible downside of forgiveness. That forgiveness has a dark side becomes patently obvious when the philosophers Murphy and Hampton (1988) remind us that "forgiveness is the sort of thing that one does for a reason, and where there are reasons there is a distinction between good ones and bad ones" (p. 15).

Forgiveness lends itself to abuse, as one realizes when recalling that a transgression places the aggrieved partner in a position of moral superiority vis-à-vis the transgressor. Undoubtedly some in relationships succumb to the temptation to abuse this position, though in the absence of data this must remain speculative. Although one might expect such behavior to occur more frequently in relationships that are dysfunctional, it is probably not exclusive to such relationships. It would therefore be useful to identify the conditions under which forgiveness is used to manipulate the partner or even as a weapon to exact revenge. Failure to do so will result in an incomplete picture of forgiveness in relationships.

\section{CONCLUSION}

This chapter has covered considerable ground, demonstrating that a good deal has been learned about forgiveness in relationships in a relatively

short time. This fact alone suggests an answer to the question posed in the chapter title. The philosopher Boleyn-Fitzgerald's (2002) conclusion that forgiveness is "arguably the most important virtue for controlling anger" ( $\mathrm{p}$. 483), which, together with Mother Teresa's observation, and most important, the data cited in this chapter, indicates that forgiveness needs to be integral to a complete science of close relationships. At the same time, it is 
apparent that William Blake's observation about the difficulty of forgiving those with whom we are in a close relationship is equally true. The challenge this poses for research on forgiveness in relationships is immense. Several issues that need to be addressed in the service of meeting this challenge were therefore identified, including the history of hurts in the relationship, the implicit versus explicit nature of forgiveness, types of forgiveness, the communication of forgiveness, and the potential downside of forgiveness.

\section{REFERENCES}

Aristotle. (1939). Rhetoric. Cambridge, MA: Harvard University Press.

Berscheid, E. (1999). The greening of relationship science. American Psychologist, $54,260-266$.

Berry, J. W., Worthington, E. L., Parrott, L., O'Connor, L. E., \& Wade, N. G. (2001). Dispositional forgivingness: Development and construct validity of the Transgression Narrative Test of Forgivingness (TNTF). Personality and Social Psychology Bulletin, 27, 1277-1290.

Boleyn-Fitzgerald, P. (2002). What should "forgiveness" mean? The Journal of Values Inquiry, 36, 483-498.

Burton, S., Gordon, K., \& Porter, L. (2004). Predicting the intentions of women in domestic violence shelters to return to partners: Does forgiveness play a role? Journal of Family Psychology, 18, 331-338.

Caprara, G. V. (1986). Indicators of aggression: The dissipation-rumination scale. Personality and Individual Differences, 7, 763-769.

Downie, R. S. (1971). Roles and values. London: Methuen.

Eaton, J., \& Struthers, C. W. (2006). The reduction of psychological aggression across varied interpersonal contexts through repentance and forgiveness. Aggressive Behavior, 32, 195-206.

Exline, J. J., Worthington, E. L., Jr., Hill, P., \& McCullough, M. E. (2003). Forgiveness and justice: A research agenda for social and personality psychology. Personality and Social Psychology Review, 7, 337-348.

Fincham, F. D. (2000). The kiss of the porcupines: From attributing responsibility to forgiving. Personal Relationships, 7, 1-23.

Fincham, F. D., \& Beach, S. R. H. (2002). Forgiveness in marriage: Implications for psychological aggression and constructive communication. Personal Relationships, 9, 239-251.

Fincham, F. D., \& Beach, S. R. H. (2007). Forgiveness and marital quality: Precursor or consequence in well-established relationships. Journal of Positive Psychology, 2, 260-268.

Fincham, F. D., Beach, S. R., \& Davila, J. (2004). Forgiveness and conflict resolution in marriage. Journal of Family Psychology, 18, 72-81. 
Fincham, F. D., Beach, S. R. H., \& Davila, J. (2007). Longitudinal relations between forgiveness and conflict resolution in marriage. Joumal of Family Psychology, 21, $542-545$.

Fincham, F. D., Hall, J. H., \& Beach, S. R. H. (2005). 'Til lack of forgiveness doth us part: Forgiveness in marriage. In E. L. Worthington (Ed.), Handbook of forgiveness (pp. 207-226). New York: Routledge.

Fincham, F. D., Jackson, H., \& Beach, S. R. H. (2005). Transgression severity and forgiveness: Different moderators for objective and subjective severity. Journal of Social and Clinical Psychology, 24, 860-875.

Fincham, F. D., \& Linfield, K. J. (1997). A new look at marital quality: Can spouses feel positive and negative about their marriage? Journal of Family Psychology, 11, 489-502.

Fincham, F. D., Paleari, G., \& Regalia, C. (2002). Forgiveness in marriage: The role of relationship quality, attributions and empathy. Personal Relationships, 9, 2737.

Friesen, M. D., Fletcher, G. J. O., \& Overall, N. C. (2005). A dyadic assessment of forgiveness in intimate relationships. Personal Relationships, 12, 61-77.

Ghandi, M. (2000). The collected works of Mahatma Gandhi (2nd rev. ed., Vol. 51, pp. 301-302). Retrieved April 2, 2008, from http://www.gandhiserve.org/cwmg/ cwmg.html

Holman, H. E., \& Silver, R. C. (2005). Future-oriented thinking and adjustment in a nationwide longitudinal study following the September 11 th terrorist attacks. Motivation and Emotion, 29, 389-410.

Holmgren, M. R. (1993). Forgiveness and the intrinsic value of persons. American Philosophical Quarterly, 30, 342-352.

Hoyt, W. T., Fincham, F., McCullough, M. E., Maio, G., \& Davila, J. (2005). Responses to interpersonal transgressions in families: Forgivingness, forgivability, and relationship-specific effects. Journal of Personality and Social Psychology, 89, 375-394.

Katz, J., Street, A., \& Arias, I. (1997). Individual differences in self-appraisals and responses to dating violence scenarios. Violence and Victims, 12, 265-276.

Kearns, J. N., \& Fincham, F. D. (2005). Victim and perpetrator accounts of interpersonal transgressions: Self-serving or relationship-serving biases? Personality and Social Psychology Bulletin, 31, 321-333.

Kelley, D. (1998). The communication of forgiveness. Communication Studies, 49, $1-17$.

Kenny, D. A., Kashy, D. A., \& Cook, W. L. (2006). Dyadic data analysis. New York: Guilford Press.

Maio, G. R., Thomas, G., Fincham, F. D., \& Carnelley, K. (2008). Unraveling the role of forgiveness in family relationships. Joumal of Personality and Social Psychology, 94, 307-319.

McCullough, M. E., Exline, J. J., \& Baumeister, R. F. (1998). An annotated bibliography of research on forgiveness and related concepts. In E. L. Worthington 
(Ed.), Dimensions of forgiveness: Psychological research and theological perspectives (pp. 193-317). Philadelphia: Templeton Press.

McCullough, M. E., Fincham, F. D., \& Tsang, J. (2003). Forgiveness, forbearance, and time: The temporal unfolding of transgression-related interpersonal motivations. Journal of Personality and Social Psychology, 84, 540-557.

McCullough, M. E., Rachal, K. C., Sandage, S. J., Worthington, E. L., Jr., Brown, S. W., \& Hight, T. L. (1998). Interpersonal forgiving in close relationships: II. Theoretical elaboration and measurement. Joumal of Personality and Social Psychology, 75, 1586-1603.

McCullough, M. E., \& vanOyen Witvliet, C. (2002). The psychology of forgiveness. In C. R. Snyder \& S. J. Lopez (Eds.), Handbook of positive psychology (pp. 446458). Oxford, England: Oxford Psychology Press.

McCullough, M. E., Worthington, E. L., Jr., \& Rachal, K. C. (1997). Interpersonal forgiving in close relationships. Journal of Personality and Social Psychology, 73, 321-336.

McNulty, J. K. (2008). Forgiveness in marriage: Putting the benefits into context. Joumal of Family Psychology, 22, 171-175.

Murphy, J., \& Hampton, J. (1988). Forgiveness and mercy. New York: Cambridge University Press.

Murray, S. L., Holmes, J. G., \& Griffin, D. W. (1996). The benefits of positive illusions: Idealization and the construction of satisfaction in close relationships. Journal of Personality and Social Psychology, 70, 79-98.

Nietzsche, F. W. (1887). The genealogy of morals. London: Society for Promoting Christian Knowledge.

Paleari, G., Regalia, C., \& Fincham, F. D. (2003). Adolescents' willingness to forgive parents: An empirical model. Parenting: Science and Practice, 3, 155-174.

Paleari, G., Regalia, C., \& Fincham, F. D. (2005). Marital quality, forgiveness, empathy, and rumination: A longitudinal analysis. Personality and Social Psychology Bulletin, 31, 368-378.

Rusbult, C. E., Verette, J., Whitney, G. A., Slovik, L. F., \& Lipkus, I. (1991). Accommodation processes in close relationships: Theory and preliminary empirical evidence. Journal of Personality and Social Psychology, 60, 53-78.

Stillwell, A. M., \& Baumeister, R. F. (1997). The construction of victim and perpetrator memories: Accuracy and distortion in role-based accounts. Personality and Social Psychology Bulletin, 23, 1157-1172.

Terzino, K., Fincham, F. D., \& Cross, S. (2008). But do you really forgive me? An implicit test of forgiveness. Unpublished manuscript.

Tsang, J., McCullough, M.E., Fincham, F. D. (2006). Forgiveness and the psychological dimension of reconciliation: A longitudinal analysis. Joumal of Social and Clinical Psychology, 25, 404-428.

Wade, N. G., Worthington, E. L., Jr., \& Meyer, J. E. (2005). But do they work?: A meta-analysis of group interventions to promote forgiveness. In E. L. Worthington, Jr. (Ed.), Handbook of forgiveness (pp. 423-440). New York: Routledge. 
Waller, N. G., \& Meehl, P. E. (1998). Multivariate taxometric procedures. Thousand Oaks, CA: Sage.

Worthington, E. L. (1998). Introduction. In E. L. Worthington (Ed.), Dimensions of forgiveness: Psychological research and theological perspectives (pp. 1-5). Philadelphia: Templeton Press.

Worthington, E. L. (2005). More questions about forgiveness: Research agenda for 2005-2015. In E. L. Worthington (Ed.), Handbook of forgiveness (pp. 557-575). New York: Routledge.

Worthington, E. L., Sandage, S. J., \& Berry, J. W. (2000). Group interventions to promote forgiveness. In M. E. McCullough, K. Pargament, \& C. Thoreson (Eds.), Forgiveness: Theory, research, and practice (pp. 228-253). New York: Guilford Press.

Worthington, E. L., \& Wade, N. (1999). The psychology of unforgiveness and forgiveness and implications for clinical practice. Journal of Social and Clinical Psychology, 18, 385-418. 